\title{
Effort expenditure following control deprivation
}

\author{
PAUL R. D'AGOSTINO and THANE S. PITTMAN \\ Gettysburg College, Gettysburg, Pennsylvania 17325
}

\begin{abstract}
The experiment was designed to obtain a direct measure of effort expenditure following control deprivation. It was found that control-deprived subjects chose to take significantly more trials before making a judgment of control than did baseline subjects. However, the additional effort expenditure did not increase either response accuracy or confidence. Several factors that may influence effort expenditure following control deprivation are discussed.
\end{abstract}

Kelley $(1967,1971)$ has suggested that attributions or causal explanations are made in the service of a general motive to have and to be able to exert effective control over the environment. Pittman and Pittman (1980) recently reported data consistent with this hypothesis; subjects deprived of control were more likely to detect and utilize causal information in a social inference task than were baseline subjects. Although subjects in that study were provided with all of the relevant information by the experimenter, one might also expect that controldeprived persons would be willing to expend effort to acquire information that could then be used to make causal analyses. Swann, Stephenson, and Pittman (1981) found indirect support for this hypothesis. When given an opportunity to select questions for an interviewee, control-deprived subjects were more likely to select highly revealing or diagnostic questions for the interviewee than were baseline subjects. This finding implies both a heightened interest in acquiring diagnostic information and a willingness to create a potentially embarrassing or awkward situation with an interaction partner to get it. However, while these findings are consistent with the predicted increase in effort, no direct measure of effort expenditure was taken. The present study was designed to obtain a more direct measure of effort expenditure following control deprivation.

The present study utilized a control-judgment task developed by Alloy and Abramson (1979) in which subjects try to determine how much control they have over the onset of a light by either pressing or not pressing a button on each trial. Unlike the procedure used by Alloy and Abramson, however, subjects in the present study were told they could have as many trials as they wished prior to making their judgment. If control deprivation leads to an increase in efforts to acquire information, then control-deprived subjects should take

This research was supported in part by National Science Foundation Grant BNS 78-17440 to Thane S. Pittman. Reprint requests should be sent to Paul R. D'Agostino, Department of Psychology, Gettysburg College, Gettysburg, Pennsylvania 17325. a greater number of trials prior to making their judgment than baseline subjects. The relationship between effort expenditure and accuracy was also examined by comparing subjects' estimates of control across conditions.

\section{METHOD}

\section{Subjects}

The subjects were 48 Gettysburg College undergraduates who received credit in partial fulfillment of a course requirement in an introductory psychology class. Subjects were randomly assigned to one of the three conditions of the experiment (control deprivation, baseline, and yoked-baseline).

\section{Procedure}

Initially, all subjects engaged in a concept-identification task described in detail by Pittman and Pittman (1979). Briefly, all subjects received 10 trials on each of six problems. Under the control-deprived condition, subjects were given noncontingent feedback on all trials with incorrect feedback given on the last trial for each problem. Under both baseline conditions, subjects were told that their task was to respond without feedback to all of the problems in order to provide a baseline for a correctionfor-guessing adjustment for other subjects. Following the conceptidentification problems, all subjects performed the controljudgment task. Subjects under the baseline and controldeprivation conditions were allowed to try as many trials as they wished prior to making their control judgment. Subjects under the yoked-baseline condition received as many trials as their designated partners in the control-deprivation condition.

The control-judgment task was introduced as a second problem solving task. Subjects were seated in front of a response console containing a response button, a red light, and a green light. Following the instructions used by Alloy and Abramson (1979), subjects were told that by pressing or not pressing the response button on each trial they were to learn what degree of control they had over whether or not the green light came on. The beginning of each trial was signaled by the onset of the red light for $3 \mathrm{sec}$. During this time, subjects were told either to press or not to press the response button. Following their response (press or not press), the green light was activated by the experimenter according to a predetermined schedule that produced $35 \%$ control. For half the subjects under each condition, the green light came on for $75 \%$ of the trials on which they pressed and for $40 \%$ of the trials on which they did not press. For the remaining subjects in each condition, the green light came on for $75 \%$ of the trials on which they did not press and for $40 \%$ of the trials on which they did press. Two different schedules, each producing $35 \%$ control, were used equally often 
in each condition. All subjects were instructed to sample both the press and not-press responses frequently. The yoked-baseline group was not told how many trials they were to be given; the baseline and control-deprived subjects were told that they could have as few or as many trials as they needed in order to make their judgment. Following the last trial, all subjects indicated their judgment of control on a scale from $0 \%$ (no control) to $100 \%$ (complete control). In addition, they indicated on a 101-point scale how confident they were in their response.

\section{RESULTS AND DISCUSSION}

Analysis of variance indicated that control-deprived subjects took significantly more trials on the average (49.81) than did baseline subjects (34.44) prior to making their control judgment $[\mathrm{F}(1,30)=4.36, \mathrm{p}<.05]$. However, as can be seen in Table 1 , the additional number of trials for the control-deprived and yokedbaseline subjects did not produce either greater accuracy or greater confidence $[\mathrm{F}(2,45)=.81, \mathrm{p}>.25$, for accuracy; $F(2,45)=.12, p>.25$, for confidence $]$.

Control-deprived subjects have been shown to be more likely to utilize available information (Pittman \& Pittman, 1980), to be more interested in highly diagnostic information (Swann, Stephenson, \& Pittman, 1981), and, in the present study, to be more willing to exert effort to obtain information than nondeprived baseline subjects are. The latter finding occurred on a task in which increased effort apparently does not translate into increased accuracy. Generally, subjects in this study tended to overestimate the amount of control they had (48.7\% judged control vs. $35 \%$ actual control), a finding similar to that obtained in Alloy and Abramson's (1979) $25 \%$ control condition.

The present results also are consistent with Alloy and Abramson's (1979) argument that control deprivation does not produce a cognitive or associative deficit. Alloy and Abramson found that depressed subjects were no less accurate on the control-judgment task than were nondepressed subjects; in the present study, subjects randomly assigned to a control-deprivation experience were as accurate as baseline subjects. Moreover, the present data clearly show enhanced rather than diminished effort expenditure following control deprivation. It should be noted that such effort enhancement was obtained using a level of control deprivation that does not produce reactance (Pittman \& Pittman, 1979, 1980).

Subjects in the present study invested more effort in information seeking when they had previously been deprived of control. There may well be some circum-
Table 1

Mean Judgment of Control (JC) and Mean Confidence Rating (CR) for Each Experimental Group

\begin{tabular}{cccc}
\hline & \multicolumn{3}{c}{ Experimental Condition } \\
\cline { 2 - 4 } $\begin{array}{c}\text { Dependent } \\
\text { Measure }\end{array}$ & $\begin{array}{c}\text { Base- } \\
\text { line }\end{array}$ & $\begin{array}{c}\text { Yoked } \\
\text { Baseline }\end{array}$ & $\begin{array}{c}\text { Control } \\
\text { Deprived }\end{array}$ \\
\hline JC & 42.7 & 49.6 & 53.8 \\
CR & 68.1 & 64.7 & 68.6 \\
\hline
\end{tabular}

stances, however, in which other effects of control deprivation and the properties of subsequent tasks might interact to produce a decrease in effort expenditure. It seems likely that both the perceived probability of task success and the available reasons for task failure play an important role. Enhanced effort seems likely when the task is perceived as permitting probable success and/or when failure can be attributed to external factors. When the possibility of failure exists and excuses are not readily available, subjects may employ an ego-defensive measure by simply withdrawing effort (Snyder, Stephan, \& Rosenfield, 1978).

\section{REFERENCES}

Alloy, L. B., \& Abramson, L. Y. Judgment of contingency in depressed and nondepressed students: Sadder but wiser. Journal of Experimental Psychology: General, 1979, 108, 441-485.

Kelley, H. H. Attribution theory in social psychology. In D. Levine (Ed.), Nebraska Symposium on Motivation (Vol. 15). Lincoln: University of Nebraska Press, 1967.

Kelley, H. H. Attribution theory in social interaction. In E. E. Jones (Ed.), Attribution: Perceiving the causes of behavior. Morristown, N.J: General Learning Press, 1971.

Pittman, N. L., \& Pittman, T. S. Effects of amount of helplessness training and internal-external locus of control on mood and performance. Journal of Personality and Social Psychology, 1979, 37, 39-47.

Pittman, T. S., \& PitTman, N. L. Deprivation of control and the attribution process. Journal of Personality and Social Psychology, 1980, 39, 377-389.

Snyder, M. L., Stephan, W. G., \& Rosenfield, D. Attributional egotism. In J. H. Harvey, W. J. Ickes, \& R. F. Kidd (Eds.), New directions in attribution research (Vol. 2). Hillsdale, N.J: Erlbaum, 1978.

Swann, W. B., Ste phenson, B., \& Pittman, T. S. Curiosity and control: On the determinants of the search for social knowledge. Journal of Personality and Social Psychology, 1981, 40, 635-642.

(Received for publication February 12, 1982.) 